\title{
Transgenerational effects alleviate severe fecundity loss during ocean acidification in a ubiquitous planktonic copepod
}

\author{
PETER THOR ${ }^{1}$ and SAM DUPONT ${ }^{2}$ \\ ${ }^{1}$ Norwegian Polar Institute, Fram Centre, 9296 Tromsø, Norway, ${ }^{2}$ Department of Biological and Environmental Sciences, \\ University of Gothenburg, 566 Kristineberg, 45178 Fiskebäckskil, Sweden
}

\begin{abstract}
Ocean acidification (OA) caused by anthropogenic $\mathrm{CO}_{2}$ emission is projected for thousands of years to come, and significant effects are predicted for many marine organisms. While significant evolutionary responses are expected during such persistent environmental change, most studies consider only short-term effects. Little is known about the transgenerational effects of parental environments or natural selection on the capacity of populations to counter detrimental OA effects. In this study, six laboratory populations of the calanoid copepod Pseudocalanus acuspes were established at three different $\mathrm{CO}_{2}$ partial pressures $\left(p \mathrm{CO}_{2}\right.$ of 400,900 and $\left.1550 \mu \mathrm{atm}\right)$ and grown for two generations at these conditions. Our results show evidence of alleviation of $\mathrm{OA}$ effects as a result of transgenerational effects in P. acuspes. Second generation adults showed a $29 \%$ decrease in fecundity at $900 \mu$ atm $\mathrm{CO}_{2}$ compared to $400 \mu \mathrm{atm}$ $\mathrm{CO}_{2}$. This was accompanied by a $10 \%$ increase in metabolic rate indicative of metabolic stress. Reciprocal transplant tests demonstrated that this effect was reversible and the expression of phenotypic plasticity. Furthermore, these tests showed that at a $p \mathrm{CO}_{2}$ exceeding the natural range experienced by $P$. acuspes (1550 $\mu \mathrm{atm}$ ), fecundity would have decreased by as much as $67 \%$ compared to at $400 \mu \mathrm{atm} \mathrm{CO}_{2}$ as a result of this plasticity. However, transgenerational effects partly reduced OA effects so that the loss of fecundity remained at a level comparable to that at $900 \mu \mathrm{atm} \mathrm{CO}_{2}$. This also relieved the copepods from metabolic stress, and respiration rates were lower than at $900 \mu \mathrm{atm} \mathrm{CO}_{2}$. These results highlight the importance of tests for transgenerational effects to avoid overestimation of the effects of OA.
\end{abstract}

Keywords: adaptation, copepod, egg production, ocean acidification, phenotypic plasticity, respiration, transgenerational transmission

Received 11 June 2014; revised version received 10 November 2014 and accepted 14 November 2014

\section{Introduction}

Marine organisms function in close interplay with the surrounding water. They are adapted to handle challenges visited upon them by predictable changes in water chemistry, and any environmental change is followed by physiological regulation of intracellular chemistry (Pörtner et al., 2004; Zhang et al., 2012). However, while this maintenance of cellular homoeostasis allows acclimatization to environmental fluctuations, it comes with an energetic cost. Animals experiencing significant environmental changes must alter their energy distribution to accommodate these changes, and during unfavourable conditions, such alterations may ultimately subtract from the energy available for growth and reproduction (Stumpp et al., 2011; Fitzer et al., 2013).

Distribution of assimilated energy is determined, through natural selection, by a set of heritable allocation 'rules' that maximizes fitness of the individual in a

Correspondence: Peter Thor, tel. +47 40613027,

fax + 47 77750501, e-mail: peter.thor@npolar.no given environment (Glazier \& Calow, 1992; Niewiarowski \& Roosenburg, 1993). But for any particular set of rules, the pattern of allocation need not be invariant. During environmental changes, phenotypic shifts in traits governing energy allocation may arise when different patterns of allocation increase lifetime reproductive success (Lardies \& Bozinovic, 2006). Such phenotypic shifts are in many cases primarily mediated by plastic physiological reactions to the environment (Gienapp et al., 2008; Sunday et al., 2014), but there is, however, a limit to phenotypic plasticity. Unexpected environmental changes may impose energetic costs of plasticity beyond sustainable levels (DeWitt et al., 1998), or the changes may fall entirely outside the phenotypic plasticity space of the organism. Under these circumstances, organisms with other allocation rule sets may be favoured (Mitton, 1997; DeWitt \& Scheiner, 2004). Should such environmental changes persist they may invoke irreversible transgenerational shifts in rates of growth and reproduction in affected populations.

At present, widespread ocean acidification (OA) is occurring. Driven by an increase in global atmospheric 
$p \mathrm{CO}_{2}$ from $280 \mu \mathrm{atm}$ at pre-industrial times to the present day $400 \mu \mathrm{atm}$ (IPCC, 2013), the global ocean mean surface $\mathrm{pH}$ has decreased from 8.13 to the present day 8.05. Ocean models predict a continuation of this trend with a further decrease in $0.4 \mathrm{pH}$ units by the year 2100 (Caldeira \& Wickett, 2005; Cao et al., 2007). These changes, which are predicted to persist for thousands of years to come, will expose marine organisms to dramatically changed chemical conditions, and significant effects are predicted for many marine animals (Kroeker et al., 2010; Dupont \& Pörtner, 2013).

Significant transgenerational responses are expected during such persistent environmental change (Sunday et al., 2011). Nevertheless, most studies have investigated only short-term physiological effects (Kelly \& Hofmann, 2013). For copepods, adults have shown little physiological response to OA in some studies (Kurihara, 2008; Mayor et al., 2012; McConville et al., 2013; Zervoudaki et al., 2014), while earlier larval stages and eggs seem more vulnerable (Fitzer et al., 2012; Cripps et al., 2014). Only a few previous studies on effects in offspring and following generations exist for copepods. One showed impairment of larval development beyond the second generation in Tisbe battagliai with significantly reduced copepodite size and changes in the chemical composition of the exoskeleton cuticle (Fitzer et al., 2012). Another study showed no effects on egg production and hatching success in Acartia tsuensis (Kurihara \& Ishimatsu, 2008).

Little is known about the transgenerational effects of parental environments, adaptation by genetic selection, or epigenetic changes in the offspring and the capacity of these processes to alleviate OA effects (Lim \& Brunet, 2013; Munday et al., 2013; Sunday et al., 2014). While the studies mentioned above do provide information on changes from one generation to the next, they fail to discover if these changes originated in transgenerational effects (including genetic adaptation) or they were caused by phenotypic plasticity in each generation. Another study tested for parental effects by egg transplantation between environments (Vehmaa et al., 2012). This study showed significant negative maternal effects of $\mathrm{pH}$ on egg-hatching success in Acartia sp. Thus, effects can be transmitted between generations, but again the study did not test for the origin or possible multigenerational consequences (including adaptation) of these effects. A few studies on other animal groups highlight the key role of adaptation and phenotypic plasticity. Reciprocal transplants of benthic polychaetes inhabiting areas containing underwater $\mathrm{CO}_{2}$ vents have shown metabolic adaptation to high $p \mathrm{CO}_{2}$ in Platyneries dumerilii but phenotypic plasticity in Amphiglena mediterranea (Calosi et al., 2013). This study showed that adaptation and phenotypic plasticity are equally viable strategies to tackle elevated $p \mathrm{CO}_{2}$ environments. Another study on the sea urchin Strongylocentrotus purpuratus has shown that such adaptation may arise from natural selection for larvae with specific alleles in genes related to membrane composition and ion transport (Pespeni et al., 2013).

In this study, we investigated transgenerational effects of OA in the calanoid copepod Pseudocalanus acuspes. Copepods of the Pseudocalanus genus are very abundant and widely distributed in temperate, subarctic, and Arctic waters (Aarbakke et al., 2011) and at times they contribute more than one-third of the total zooplankton biomass in the North Atlantic (Head et al., 2003; Thor et al., 2005; Drif et al., 2010). For this study, OA effects on fecundity and metabolism were tested at three different $p \mathrm{CO}_{2} \mathrm{~s}(400,900$ and $1550 \mu \mathrm{atm})$ during two generations. The possibility that transgenerational effects could counter OA effects was tested by measuring egg production rates, egg clutch sizes and respiration rates during reciprocal transplant tests (DeWitt \& Scheiner, 2004). While these tests detect transgenerational effects, they cannot distinguish between genetic adaptation and other transgenerational effects. Throughout this study, we therefore use the term 'transgenerational' in its literal sense to describe the transmission of trait changes from one generation to the next. As such, the term covers genetic, epigenetic, somatic and any other detectable trait change transmitted to the next generation.

\section{Materials and methods}

Copepods were caught in the Gullmar Fjord, Skagerrak $\left(58^{\circ} 16^{\prime} \mathrm{N}, 11^{\circ} 26^{\prime} \mathrm{E}\right)$ by oblique tows of a $200 \mu \mathrm{m}$ WP-2 plankton net equipped with a closed cod end. The net was towed from approximately $40 \mathrm{~m}$ to the surface. On board, the net samples were diluted in $25 \mathrm{~L}$ of $0.3 \mu \mathrm{m}$ filtered sea water produced from water collected at $40 \mathrm{~m}$. Samples were then brought to a cold room at the nearby Sven Lovén Centre for Marine Science, Kristineberg (SLC-K) set to the ambient water temperature during sampling $\left(5^{\circ} \mathrm{C}\right)$. In the laboratory, approximately 1000 adult Pseudocalanus spp. were sorted into two 40-L holding tanks until incubation start. The exclusive presence of $P$. acuspes was ensured by pipetting a subsample of approximately 100 individuals into RNAlater for molecular species identification by PCR. DNA was extracted using the DNeasy tissue DNA extraction kit (Qiagen), and PCR was run using primers specific for P.acuspes, P. minutus and P. elongatus (Gudmundsdottir, 2008; Grabbert et al., 2010).

\section{$\mathrm{CO}_{2}$ incubations}

Six unique copepod laboratory populations were established by transferring approximately 200 adults (generation $\mathrm{F}_{0}$ ) to 40-L experimental tanks containing $0.3 \mu \mathrm{m}$ filtered sea water. The water was then adjusted to three different $p \mathrm{CO}_{2} \mathrm{~s}$ during 
3 days (Table 1 ). $F_{0}$ females were allowed to produce eggs for 2 weeks. At this time, no $F_{1}$ copepodites had yet appeared. Tank volumes were then reduced to $10 \mathrm{~L}$ by siphoning off approximately $30 \mathrm{~L}$ from the inside of a large $50-\mu \mathrm{m}$ sieve inserted into the tanks, all $\mathrm{F}_{0}$ adults removed, and the $\mathrm{F}_{1}$ generation was introduced into new clean tanks. This procedure was repeated for the transition from $F_{1}$ to $F_{2}$. The copepods were reared at a $12 \mathrm{~h} / 12 \mathrm{~h}$ light/dark cycle at $5{ }^{\circ} \mathrm{C}$ until generation $\mathrm{F}_{2}$ reached maturity (137 days). Satiating food concentrations were achieved by pumping exponentially growing Rhodomonas baltica into the tanks (Table 1). Water was changed every second week by siphoning off $30 \mathrm{~L}$ as above and reintroducing copepods into new clean tanks.

$\mathrm{pH}$ was controlled by $\mathrm{pH}$ computers (Aqua Medic, Germany) in populations 3-6. The computers monitored $\mathrm{pH}$ and adjusted it to target levels by dynamically controlling bubbling of pure $\mathrm{CO}_{2}$ into the tanks. $\mathrm{CO}_{2}$ was administered to the bottom of the tanks at 1 bubble s$^{-1}$ next to the aeration bubbling, which was kept at 4 bubbles $\mathrm{s}^{-1}$ to efficiently mix carbonized water into the tanks. The electrodes were placed inside the stream of bubbles to achieve fast responses and prevent undershooting target $\mathrm{pHs}$ during bubbling. Once a week, $\mathrm{pH}_{\mathrm{TS}}$ was measured with a Metrohm $827 \mathrm{pH}$ meter (Metrohm, Switzerland) calibrated against a four-point temperature TRIS standard curve, and total alkalinity was measured by titration of $25 \mathrm{~mL}$ samples in a SI Analytics Titroline potentiometric titrator (Riebesell et al., 2010). $p \mathrm{CO}_{2} \mathrm{~S}$ were calculated in $\mathrm{CO}_{2} \mathrm{SYS}$ version 1.4 (Lewis \& Wallace, 1998). Food concentrations were measured every second day on an Elzone 5380 electronic particle counter.

Transgenerational effects were tested by measuring egg production rates, clutch sizes, and respiration rates during reciprocal transplant tests on $\mathrm{F}_{2}$ adults. Copepods were transplanted from 400 to 900 and $1550 \mu \mathrm{atm} \mathrm{CO}_{2}$ and from 900 to $400 \mu \mathrm{atm} \mathrm{CO}_{2}$, and from 1550 to $400 \mu \mathrm{atm} \mathrm{CO}_{2}$ (arrows in Figs 1 and 3 show transplant directions). For this purpose, each $400 \mu$ atm laboratory population was divided by volume in thirds, and every third was reintroduced to new tanks and adjusted to $400 \mu \mathrm{atm} \mathrm{CO}_{2}, 900 \mu \mathrm{atm} \mathrm{CO}_{2}$ and $1550 \mu \mathrm{atm} \mathrm{CO}_{2}$. Similarly, halves of each of the 900 and $1550 \mu$ atm laboratory populations were reintroduced to new tanks and adjusted to $400 \mu$ atm $\mathrm{CO}_{2}$ and their original $p \mathrm{CO}_{2}$. Transplanted populations then consisted purely of adults. Incubations of all original populations and transplants were then continued for 21 days to allow fertilization of unfertilized females and ensure a full egg production cycle before measurements. Egg production rates, egg clutch sizes and respiration rates were measured immediately thereafter.

The importance of phenotypic plasticity and transgenerational transmission of trait changes was estimated from changes in egg production, egg clutch size and respiration caused by transplantation. Phenotypic plasticity was inferred when changes were statistically similar in both transplant directions. Accordingly, transgenerational effects were inferred from statistically dissimilar changes between the two transplant directions (DeWitt \& Scheiner, 2004).

\section{Egg production and respiration measurements}

Rates of respiration and egg production were measured in 10 or 6 replicate samples from all original populations and their transplants (10 replicates in original populations and six replicates in transplants). In each replicate, five egg-carrying females were transferred to 1.6-mL vials fitted with fluorescent $\mathrm{O}_{2}$ foil discs (PSt3 spots, PreSens Precision Sensing, Germany) and filled with sea water adjusted to the corresponding $p \mathrm{CO}_{2}$. Vials were then sealed with Teflon caps, and $\mathrm{O}_{2}$ concentrations were measured at 0,3 and $6 \mathrm{~h}$ using a Fibox 3 optode system. Respiration rates $\left(\mathrm{nmol} \mathrm{O}_{2}\right.$ ind $^{-1}$ day $^{-1}$ ) were calculated by subtracting the average oxygen depletion rate measured in five controls from the oxygen depletion rate in the vials holding copepods, multiplying by vial volume and dividing by number of individuals in each vial. Prior testing of the optode system at $5{ }^{\circ} \mathrm{C}$ showed a $2 \mathrm{~min} 95 \%$ reaction time, that is the period of time taken before the output reached within 5\% of the final oxygen concentration value (as estimated by exponential regression). Therefore, at every sampling, oxygen concentrations were read for $3 \mathrm{~min}$, and an average of values read during the last minute was used for calculations.

Subsequently, all females were transferred to Petri dishes containing $0.3 \mu \mathrm{m}$ filtered sea water, photographed under a stereoscope and incubated for 12-18 days for daily counts of carried eggs. One drop of R. baltica was administered to each dish every third day to prevent female mortality (final

Table 1 Average experimental conditions during the incubation period

\begin{tabular}{|c|c|c|c|c|c|}
\hline Population & $\begin{array}{l}\text { Temperature } \\
{ }^{\circ} \mathrm{C}\end{array}$ & $\begin{array}{l}p \mathrm{CO}_{2} \\
\mu a t m\end{array}$ & $\mathrm{pH}_{\mathrm{TS}}$ & $\begin{array}{l}\mathrm{A}_{\mathrm{T}} \\
\mu \mathrm{mol} \mathrm{kg}{ }^{-1}\end{array}$ & $\begin{array}{l}\text { Food conc. } \\
\mu \mathrm{gC} \mathrm{L} \mathrm{L}^{-1}\end{array}$ \\
\hline 1 & $5.68 \pm 0.50^{\mathrm{a}}$ & $410 \pm 96^{\mathrm{a}}$ & $8.05 \pm 0.07^{\mathrm{a}}$ & $2382 \pm 205^{\mathrm{a}}$ & $692 \pm 229^{a}$ \\
\hline 2 & $5.74 \pm 0.45^{\mathrm{a}}$ & $402 \pm 118^{\mathrm{a}}$ & $8.07 \pm 0.09^{a}$ & $2454 \pm 100^{\mathrm{a}}$ & $761 \pm 173^{a}$ \\
\hline 3 & $5.36 \pm 0.76^{\mathrm{a}}$ & $890 \pm 107^{b}$ & $7.75 \pm 0.09^{b}$ & $2491 \pm 93^{\mathrm{a}}$ & $876 \pm 422^{a}$ \\
\hline 4 & $5.67 \pm 0.37^{\mathrm{a}}$ & $909 \pm 221^{b}$ & $7.75 \pm 0.10^{\mathrm{b}}$ & $2473 \pm 121^{\mathrm{a}}$ & $769 \pm 225^{a}$ \\
\hline 5 & $5.53 \pm 0.66^{\mathrm{a}}$ & $1549 \pm 251^{\mathrm{c}}$ & $7.54 \pm 0.08^{c}$ & $2470 \pm 93^{\mathrm{a}}$ & $707 \pm 240^{a}$ \\
\hline 6 & $5.55 \pm 0.45^{\mathrm{a}}$ & $1558 \pm 272^{c}$ & $7.54 \pm 0.14^{\mathrm{c}}$ & $2547 \pm 165^{\mathrm{a}}$ & $736 \pm 138^{a}$ \\
\hline
\end{tabular}

$\mathrm{pH}_{\mathrm{TS}}$ is total scale $\mathrm{pH}, \mathrm{A}_{\mathrm{T}}$ is total alkalinity, and $p \mathrm{CO}_{2}$ is $\mathrm{CO}_{2}$ partial pressure. Food concentrations were transformed to $\mu \mathrm{gC} \mathrm{L}^{-1}$ according to Montagnes et al. (1994). Superscript letters indicate groups of values with no significant difference (1-factor ANOvAs with Holm-Sidak post hoc test: $P<0.05)$. 


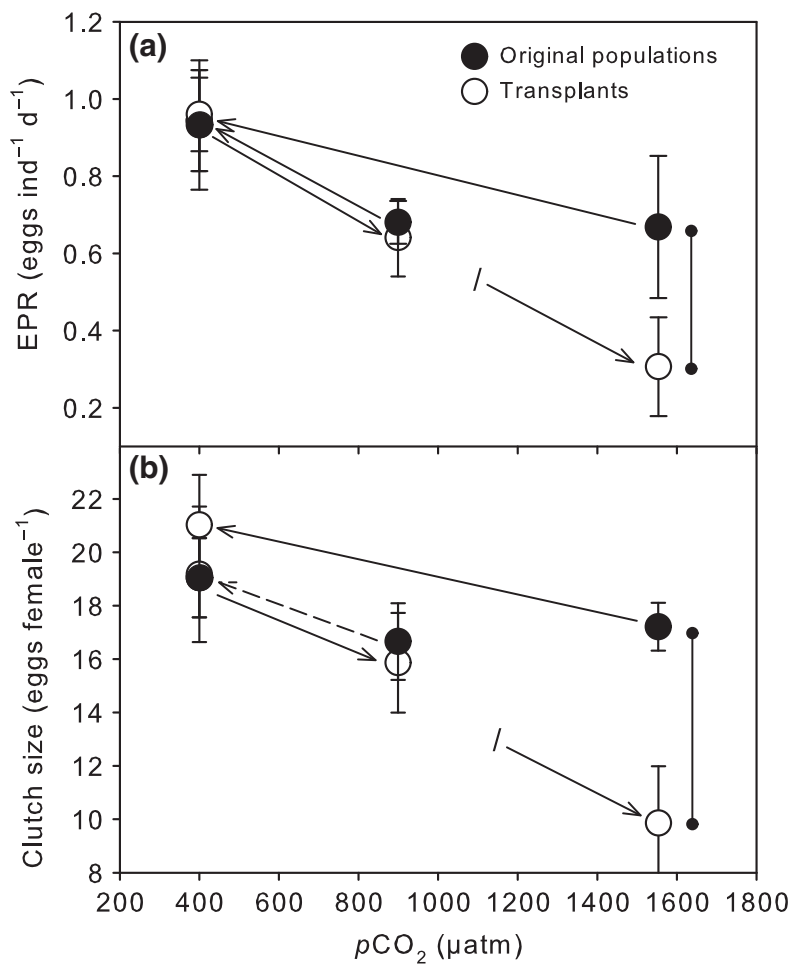

Fig. 1 (a) Egg production rates (EPR) and (b) egg clutch sizes in Pseudocalanus acuspes incubated at three $p \mathrm{CO}_{2} \mathrm{~S}$ for two generations (137 days). Filled circles show results for second generation females of the originally incubated laboratory populations, and open circles show results for second generation females 3 weeks after transplantation to alternate $p \mathrm{CO}_{2} \mathrm{~s}(n=6$ or 10 for each treatment). Error bars depict $95 \%$ confidence intervals. Arrows between filled and open circles show transplant directions. Arrows from $400 \mu \mathrm{atm} \mathrm{CO}_{2}$ to $1550 \mu \mathrm{atm} \mathrm{CO}_{2}$ are truncated to the left for clarity (shown by the dash). Significant and nonsignificant changes (Student-Newman-Keul's and Holm-Sidak post hoc tests) are showed by solid and hatched arrows, respectively. Significant differences between transplant and original target populations are shown by vertical lines with point ends.

concentration ca. $300 \mu \mathrm{gC} \mathrm{L} \mathrm{L}^{-1}$ ). Egg production rates (eggs ind $^{-1}$ day $^{-1}$ ) were calculated as the slopes of linear regressions on daily egg counts $\left(\right.$ day $^{-1}$ ) multiplied by initial number of eggs counted on the photographs (eggs female ${ }^{-1}$ ) assuming egg production rates to equal hatching rates (Runge \& Roff, 2000).

\section{Data analysis}

Because the design of the reciprocal transplantations included only two environmental states, the phenotypic changes were analysed as character state changes. This is opposed to the reaction norm analysis model, which would otherwise be used to test for phenotypic reactions to continuous scale variables such as $p \mathrm{CO}_{2} / \mathrm{pH}$. However, it has been shown that the two models are mathematically similar, the character state model being a special case of the reaction norm model (de Jong, 1995), and to avoid using the implicit regression analysis of the reaction norm model on two-point data, we applied the character state model. Accordingly, differences in means of egg production rates, clutch sizes and respiration rates were tested among populations (both original and transplant populations) by ANOVA. For these tests, the experimental units were the random samples of five females from each population (Hurlbert, 1984). Replication of populations enabled conclusions that observed differences were caused by divergent due to the $p \mathrm{CO}_{2}$ and not by chance events during the incubations. This was taken into account by applying an ANOVA design where 'population' was nested within ' $p \mathrm{CO}_{2}$ ' population $\left(p \mathrm{CO}_{2}\right)$. Levene's test was used to assure homoscedasticity.

\section{Results}

Egg production and respiration in original populations

After two generations, egg production rates were significantly depressed at 900 and $1550 \mu$ atm $\mathrm{CO}_{2}$ compared to at $400 \mu \mathrm{atm} \mathrm{CO}_{2}$. Rates were $0.945 \pm 0.183$ eggs ind ${ }^{-1}$ day $^{-1}$ (mean \pm SD) at $400 \mu$ atm $\mathrm{CO}_{2}, 0.681$ \pm 0.078 eggs ind ${ }^{-1}$ day $^{-1}$ at $900 \mu$ atm $\mathrm{CO}_{2}$ and 0.668 \pm 0.240 eggs ind ${ }^{-1}$ day $^{-1}$ at $1550 \mu$ atm $\mathrm{CO}_{2}$ (Fig. 1a, filled circles) (1-factor nested ANOVA, $p \mathrm{CO}_{2}: F_{6,57}=16.1$, $P<0.001$, population $\left(p \mathrm{CO}_{2}\right): F_{6,57}=0.99, P=0.44$, Student-Newman-Keul's post hoc test) (Table 2). While there were no significant differences in egg diameter relative to female prosome length among laboratory populations $\quad(0.124 \pm 0.054, \quad$ mean \pm SD) $\quad$ (1-factor nested ANOVA: $F_{2,15}=0.345, P=0.71$ ), mean egg clutch sizes were also significantly reduced from $19.0 \pm 2.1$ eggs ind ${ }^{-1}$ at $400 \mu$ atm $\mathrm{CO}_{2}$ to $16.7 \pm 2.0 \mathrm{eggs}^{-1}$ at $900 \mu$ atm $\mathrm{CO}_{2}$ and $17.2 \pm 1.2$ eggs ind $^{-1}$ at $1550 \mu$ atm $\mathrm{CO}_{2}$ (Fig. 1b, filled circles) (1-factor nested ANOvA, $p \mathrm{CO}_{2}: F_{6,57}=18.3, P<0.001$ and population $\left(p \mathrm{CO}_{2}\right)$ : $F_{6,57}=0.28, P=0.95$, Student-Newman-Keul's post hoc test) (Table 2).

Egg-hatching rates were constant during the 12 18 days the eggs and females were kept in Petri dishes so that the fraction of eggs remaining in clutches decreased linearly with time in all populations (Fig. 2) (linear regressions: $P<0.05$ ). Egg-hatching rates (slopes in Fig. 2) decreased significantly with increasing $p \mathrm{CO}_{2}$ among original populations (1-factor nested ANOVA, $p \mathrm{CO}_{2}: F_{6,57}=3.88, P=0.003$, population $\left(p \mathrm{CO}_{2}\right)$ : $\left.F_{6,57}=1.10, P=0.38\right)$. All eggs were hatched after 17 days, which indicates that the 21 days acclimation period after the transplantations were sufficient to allow full acclimation of egg production rates. Hence, assuming equal rates of egg production and hatching, an assumption necessary for estimates of egg production in egg-carrying copepods (Runge \& Roff, 2000), all 
Table 2 Results of Student-Newman-Keul's post hoc tests following ANOVA tests on (a) egg production rates, (b) egg clutch sizes and (c) respiration rates

\begin{tabular}{|c|c|c|c|c|c|}
\hline \multirow[b]{2}{*}{ Treatment } & \multirow[b]{2}{*}{$n$} & \multicolumn{4}{|c|}{ Subsets } \\
\hline & & 1 & 2 & 3 & 4 \\
\hline \multicolumn{6}{|c|}{ (a) Egg production rate (eggs female ${ }^{-1}$ day $^{-1}$ ) } \\
\hline 400 & 10 & & & 0.945 & \\
\hline 900 to 400 & 6 & & & 0.935 & \\
\hline 1550 to 400 & 6 & & & 0.962 & \\
\hline 900 & 10 & & 0.681 & & \\
\hline 400 to 900 & 10 & & 0.641 & & \\
\hline 1550 & 10 & & 0.668 & & \\
\hline 400 to 1550 & 6 & 0.307 & & & \\
\hline \multicolumn{6}{|c|}{ (b) Egg clutch size (eggs female ${ }^{-1}$ ) } \\
\hline 400 & 10 & & & 19.0 & 19.0 \\
\hline 900 to 400 & 6 & & & 19.2 & 19.2 \\
\hline 1550 to 400 & 6 & & & & 21.0 \\
\hline 900 & 10 & & 16.7 & 16.7 & \\
\hline 400 to 900 & 10 & & 15.9 & & \\
\hline 1550 & 10 & & 17.2 & 17.2 & \\
\hline 400 to 1550 & 6 & 9.9 & & & \\
\hline \multicolumn{6}{|c|}{ (c) Respiration rate $\left(\mathrm{nmol} \mathrm{O}_{2}\right.$ ind $^{-1}$ day $^{-1}$ ) } \\
\hline 400 & 10 & 3.63 & 3.63 & & \\
\hline 900 to 400 & 6 & & 3.89 & 3.89 & \\
\hline 1550 to 400 & 6 & 3.37 & 3.37 & & \\
\hline 900 & 10 & & & 4.15 & \\
\hline 400 to 900 & 10 & & 3.94 & 3.94 & \\
\hline 1550 & 10 & 3.07 & & & \\
\hline 400 to 1550 & 6 & & 3.91 & 3.91 & \\
\hline
\end{tabular}

Similar results were obtained with Holm-Sidak post hoc tests. $n$ is number of replicates. Significantly, equal groups are arranged into subsets and values show average rates. Observed power $\geq$ is 0.99 for all three tests.

eggs were produced after the transplantations. Thus, egg production rates completely reflected the transplant environment.

Oxygen concentrations decreased between $14 \%$ and $21 \%$ during the 6-h respiration rate incubations, and all individuals appeared unharmed at the end of the incubation period. Respiration rates were significantly higher in the original $900 \mu \mathrm{atm}$ populations (1factor nested ANOVA, $p \mathrm{CO}_{2}: F_{6,53}=7.49, P<0.001$, population $\left(p \mathrm{CO}_{2}\right): F_{6,53}=0.56, P=0.68$, Student-Newman-Keul's post hoc test) (Table 2). They increased from $3.63 \pm 0.31 \mathrm{nmol} \mathrm{O}_{2}$ ind $^{-1}$ day $^{-1}$ at $400 \mu \mathrm{atm} \mathrm{CO}_{2}$ to $4.15 \pm 0.27 \mathrm{nmol} \mathrm{O}_{2}$ ind $^{-1}$ day $^{-1}$ at $900 \mu \mathrm{atm} \mathrm{CO}_{2}$, but then decreased to $3.07 \pm 0.53 \mathrm{nmol} \mathrm{O}_{2}$ ind $^{-1}$ day $^{-1}$ at $1550 \mu$ atm $\mathrm{CO}_{2}$ (Fig. 3, filled circles).

\section{Effects of reciprocal transplants}

The reciprocal transplant tests showed significant effects in egg production rates and clutch sizes, but not in respiration rates (Figs 1 and 3). All transplantations induced significant changes in egg production rates (solid arrows in Fig. 1a). Furthermore, egg production rates were fully reversible between 400 and $900 \mu$ atm $\mathrm{CO}_{2}$. There were no significant differences between rates in the 400 to $900 \mu \mathrm{atm}$ transplants and rates in the original $900 \mu \mathrm{atm}$ populations. Similarly, there were no differences between rates in the 900 to $400 \mu$ atm transplants and original $400 \mu \mathrm{atm}$ populations. Thus, changes in egg production rates were the result of phenotypic plasticity at this level of OA. On the other hand, while there were no significant differences between the 1550 to $400 \mu \mathrm{atm}$ transplants and original $400 \mu \mathrm{atm}$ populations, we found significant differences between the 400 to $1550 \mu \mathrm{atm}$ transplants and original $1550 \mu \mathrm{atm}$ populations. Hence, changes in egg production rates were not reversible between 400 to $1550 \mu$ atm $\mathrm{CO}_{2}$ indicating transgenerational transmission of changes in egg production rates. Clutch sizes showed similar effects. Although clutch sizes did not change significantly in the 900 to $400 \mu \mathrm{atm}$ transplants, all other transplantations had significant effects. This indicates that changes in clutch sizes were also induced by phenotypic plasticity between 400 to $900 \mu \mathrm{atm} \mathrm{CO}_{2}$, but the result of transgenerational effects between 400 and $1500 \mu \mathrm{atm} \mathrm{CO}_{2}$. The 400 to $1550 \mu \mathrm{atm}$ transplants showed a decrease in egg production rate to 0.31 eggs ind $^{-1}$ day $^{-1}$ and clutch size to $9.86 \pm 2.03 \mathrm{eggs}$ ind $^{-1}$. These correspond to decreases of $67 \%$ and $43 \%$, respectively. In comparison, the original $1550 \mu \mathrm{atm}$ populations showed values for egg production rate and clutch size that were only $29 \%$ and $10 \%$ lower than in the $400 \mu$ atm populations.

Although the original 400 and $900 \mu$ atm populations showed significantly different respiration rates, there were no significant differences between any of the two transplants and the original populations at the target $p \mathrm{CO}_{2}$ (Table 2). Hence, the differences in respiration rates between the $400 \mu \mathrm{atm}$ and $900 \mu \mathrm{atm}$ populations were caused by phenotypic plasticity. On the other hand, the 400 to $1550 \mu$ atm transplants did show rates significantly different than in the original $1550 \mu \mathrm{atm}$ populations (Table 2). There was no difference between the reciprocal transplants and the original populations (the 1550 to $400 \mu \mathrm{atm}$ transplants and the original $400 \mu \mathrm{atm}$ populations), and this indicates a transgenerational development of different reaction norms of respiration at this level of $\mathrm{OA}$.

\section{Discussion}

Pseudocalanus acuspes experienced significantly diminished fecundity when subjected to increased $p \mathrm{CO}_{2}$ during two generations. But most importantly, trans- 


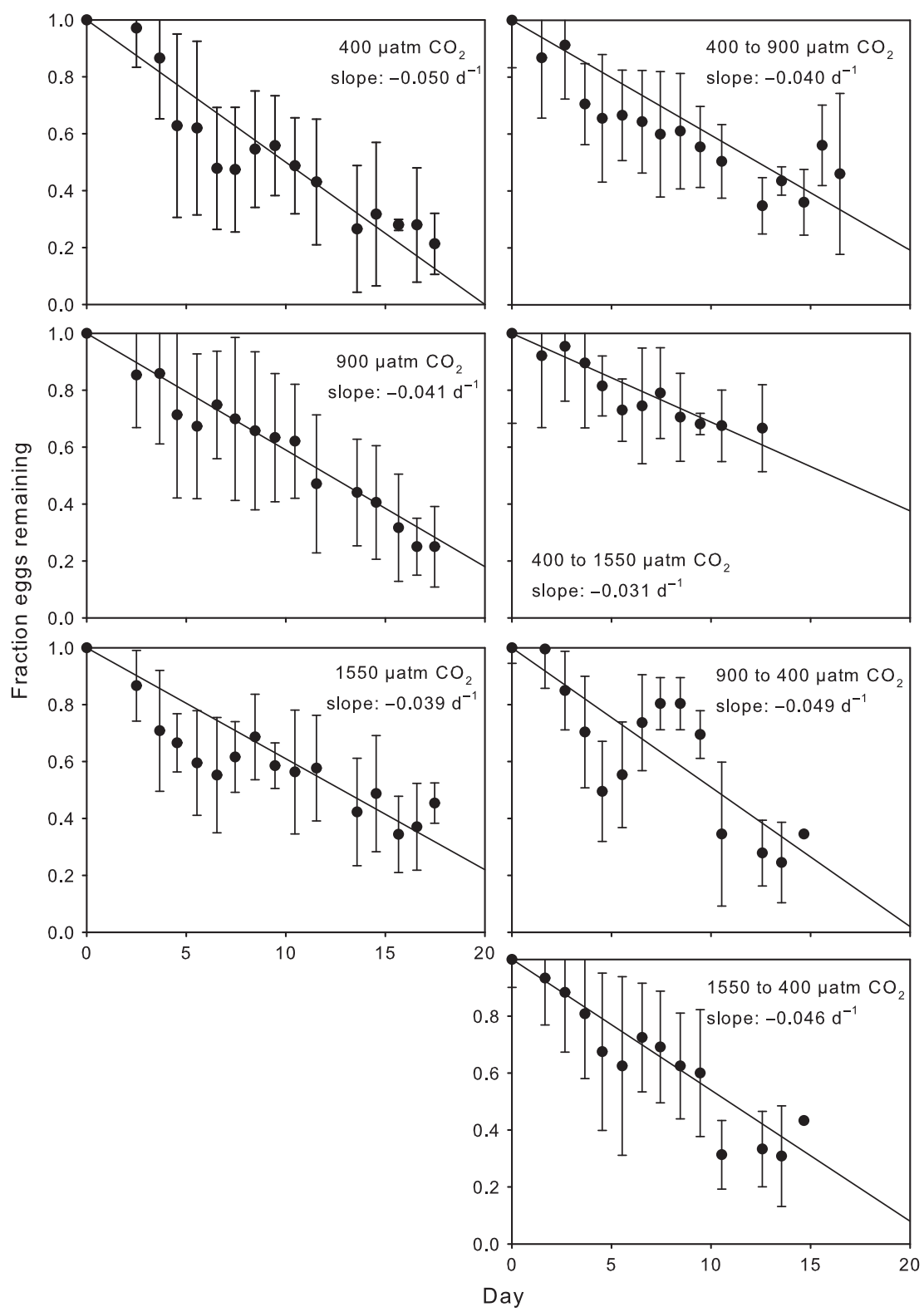

Fig. 2 Decline in mean $( \pm \mathrm{SD})$ number of eggs clutch ${ }^{-1}$ during the 12- to 18-day incubations for hatching rate estimates. Original laboratory populations (left panels) and transplants (right panels). Lines show mean slopes of all replicates ( $n=6$ or 10 for each replicate). The slopes correspond to mean hatching rates $\left(\right.$ day $\left.^{-1}\right)$, which were used to calculate egg production rates.

generational effects partly alleviated this loss at $1550 \mu \mathrm{atm} \mathrm{CO}_{2}$, and the magnitude of the negative response was only half of what would have resulted from a response caused solely by phenotypic plasticity. All changes between 400 to $900 \mu \mathrm{atm} \mathrm{CO}_{2}$ were fully reversible and attributable to phenotypic plasticity; hence, our data suggest that transgenerational effects set in at $p \mathrm{CO}_{2} \mathrm{~S}$ above the present range of environmental variability (400-900 $\mu \mathrm{atm} \mathrm{CO}_{2}$, Dorey et al., 2013).

The observed depressed egg production rates contrast with some previous short-term effect studies $(<1$ generation) in pelagic copepods. Studies on different copepod species have shown no effects on mortality, egg production or larval development up to $2000 \mu \mathrm{atm}$ $\mathrm{CO}_{2}$ (Kurihara et al., 2004; Kurihara \& Ishimatsu, 2008; Mayor et al., 2012; McConville et al., 2013). The copepod exoskeleton contains little $\mathrm{CaCO}_{3}$, so no direct impairment by shell dissolution or decreased rates of calcification is expected. However, variations in other physiological processes in affected organisms, calcifiers and non-calcifiers alike, may instigate diminished performance. Recently, reduced egg production and increased naupliar mortality were observed in $A$. tonsa (Cripps et al., 2014), a species otherwise known to toler- 


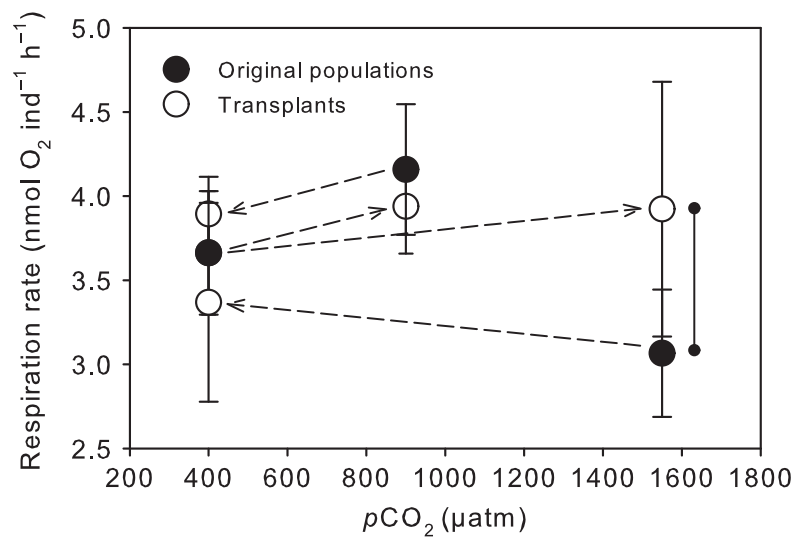

Fig. 3 Respiration rates in Pseudocalanus acuspes incubated at three $p \mathrm{CO}_{2} \mathrm{~s}$ for two generations (137 days). Filled circles show rates for second generation females of the originally incubated laboratory populations, and open circles show rates for second generation females 3 weeks after transplantation to alternate $p \mathrm{CO}_{2} \mathrm{~S}$ ( $n=6$ or 10 for each treatment). Error bars depict $95 \%$ confidence intervals. Arrows between filled and open circles show transplant directions. Significant and nonsignificant changes (Student-Newman-Keul's and Holm-Sidak post hoc tests) are showed by solid and hatched arrows, respectively. Significant differences between transplant and original target populations are shown by vertical lines with point ends.

ate wide changes in water chemistry (Calliari et al., 2006). Cripps et al. (2014) found significantly increased naupliar mortality and significantly decreased egghatching success already at $1000 \mu \mathrm{atm} \mathrm{CO}_{2}$ and very severe effects at $2000 \mu \mathrm{atm} \mathrm{CO}_{2}$. Moreover, Lewis et al. (2013) found increased mortality in Arctic Calanus glacialis nauplii and Oithona similis nauplii and adults already at $700 \mu \mathrm{atm} \mathrm{CO}_{2}$. They observed more severe effects in O. similis than in C. glacialis, and they argue that $O$. similis is adapted to a more narrow range of $\mathrm{pH}$ due to the more shallow vertical migration patterns of this species. Both $P$. acuspes and A. tonsa show similar shallow migration compared to the Calanus species.

One possible explanation for the observed suboptimal performance may be less than optimal energy allocation due to environmental stress. For instance, due to the increased metabolic rates at $1271 \mu$ atm $\mathrm{CO}_{2}$, sea urchin pluteus larvae were not able to allocate more than $39-45 \%$ of the available energy to growth, while larvae growing under present-day conditions could allocate $78-80 \%$ of the available energy (Stumpp et al., 2011). Such reallocation has also been hypothesized for the copepod Tispe battagliai. By combining data for growth, cuticle composition and nauplii production, Fitzer et al. (2012) argued that copepods will preferentially reallocate energy resources to maintain the reproductive output at the expense of larval growth. Our results showed considerable decoupling of respiration and production so that respiration rates were significantly higher at $900 \mu \mathrm{atm} \mathrm{CO}_{2}$ compared to $400 \mu \mathrm{atm} \mathrm{CO}_{2}$ despite the decrease in egg production rate. As a result, the ratio between respiration and egg production was twice as high in the $900 \mu$ atm populations as in the $400 \mu \mathrm{atm}$ populations. In unstressed individuals, respiration and production are coupled through specific dynamic action effects (SDA, i.e. increase in metabolic rate due to biosynthesis during food intake) and any change in production is inevitably followed by a similar change in respiration (Thor, 2000). The respiratorial decoupling observed in the $900 \mu \mathrm{atm}$ populations suggests increased metabolic costs associated with elevated $p \mathrm{CO}_{2}$. Several previous studies of other environmental stressors in copepods support this notion. For instance, copepods experiencing changes in prey quality exhibit significantly altered SDA (Thor et al., 2002), and the respiration/egg production ratio (another proxy for SDA effects) increases in copepods experiencing stress related to decreasing salinity (Calliari et al., 2006).

Knowledge on the influence of OA on cellular metabolic processes in copepods is scarce, and it is difficult to pinpoint what metabolic changes may be responsible for the decreased performance in P. acuspes. One may speculate that increased metabolism curtailed from increased expenses for maintaining homoeostasis. Sea urchins, Strongylocentrotus droebachiensis, experience increased protein metabolism during prolonged exposure to increased $p \mathrm{CO}_{2}$, and Stumpp et al. (2012) concluded that this is to support homoeostasis by enhanced net proton extrusion. In most aquatic crustaceans, decreased cytosolic $\mathrm{pH}$ is counteracted primarily by ion exchange over the cell membrane (Henry \& Wheatly, 1992). This process demands energy, and in Krill, Euphausia superba, elevated $p \mathrm{CO}_{2}$ induces increased activity of enzymes involved in cycling of ATP and NADH, along with a decrease in body protein content (Saba et al., 2012). We hypothesise that P. acuspes may have experienced similar effects at $900 \mu \mathrm{atm}$ $\mathrm{CO}_{2}$ and that this caused the observed decrease in egg production and increase in respiration rates.

The reciprocal transplantation tests allowed discrimination of effects into transgenerational effects and effects caused by phenotypic plasticity. These tests showed that the $29 \%$ decrease in egg production rate was partly a result of transgenerational effects. Without such effects, egg production rates would have decreased by as much as $67 \%$. No previous studies address the importance of transgenerational effects to counter $\mathrm{pH}$ stress in copepods. Previous multigenerational studies have revealed deleterious effects in larval development during consecutive generations in the copepod Tispe battagliai (Fitzer et al., 2012), but no 
effects on egg production or larval development in another copepod species, Acartia tsuensis (Kurihara \& Ishimatsu, 2008). Fitzer et al. (2012) applied a model to predict changes in larval development through the coming 100 years. Because this study applied a multigenerational approach, it incorporated possible evolutionary or transgenerational effects (although these could not be detected in the applied experimental design). This approach is probably the best we can offer in terms of predictions for the future without knowledge on transgenerational effects. However, as mentioned by the authors themselves, the model assumes an inability of the copepods to adapt. Much emphasis has been put on the importance of adaptation during future global change (Munday et al., 2013; Sunday et al., 2014). We found transgenerational effects already after two generations, which could be a result of adaptation. Consequently, predictions based on models like the one applied by Fitzer et al. (2012) will overestimate OA effects. Moreover, the transgenerational effects at $1550 \mu \mathrm{atm} \mathrm{CO}_{2}$ induced an entirely different reaction to $p \mathrm{CO}_{2}$ variations, with less steep reaction norms. The implication is that future generations will experience dampened reactions of fecundity also to natural shortterm $\left(<1\right.$ generation) variations in $\mathrm{pH} / p \mathrm{CO}_{2}$. The ecological ramifications are that future $\mathrm{OA}$, at least to the level of $1550 \mu \mathrm{atm} \mathrm{CO}_{2}$, may induce more resilience towards $\mathrm{pH}$ variability in $P$. acuspes. But whether or not this will override any other negative effects imposed by, for example, coselection in fitness-related traits responsible for buffering of other environmental variables remains to be seen.

Zooplankton, including copepods, are able to adapt to environmental changes (Dam, 2013). Acartia hudsonica has shown transgenerational alleviation of detrimental effects of frequent blooms of toxic dinoflagellates in traits such as ingestion, development and egg production (Colin \& Dam, 2002), and subsequent studies indicate that these effects were in fact due to adaptation through evolutionary selection (Avery \& Dam, 2007). Moreover, while Tigriopus californicus has shown surprisingly little capacity for adaptation to increasing temperature (Kelly et al., 2012), Scottolana canadensis shows significant latitudinal transgenerational differentiation in development, adult body size and somatic growth. Unfortunately, this study did not provide any clue to the origin of the transgenerational effects; whether they are a result of natural selection or some nongenetic transgenerational transmission of trait changes (Lonsdale \& Levinton, 1985). The observed transgenerational effects in the present study may be a consequence of both. There are indications in previous studies that suggest the possibility of evolutionary adaptation to $\mathrm{OA}$ in invertebrates. Allelic shifts in genes coding for enzymes involved in membrane composition and cellular homoeostasis have been observed in sea urchin pluteus larvae during OA perturbation experiments (Pespeni et al., 2013). These shifts allowed physiological compensation to such a degree that normal developmental and morphological progress was upheld at $900 \mu \mathrm{atm} \mathrm{CO}_{2}$. Adaptation through evolutionary selection can be fast and occur even from one generation to the next in invertebrates. The oligochaete Tubifex tubifex showed increased $\mathrm{Hg}$ tolerance after exposure for only one generation (Vidal \& Horne, 2009). This tolerance was maintained in subsequent outcrosses with nontolerant control groups, a clear indication of natural selection for $\mathrm{Hg}$ tolerance. Accordingly, one could hypothesize that the changes observed in the present study were based in natural selection. But, they could also occur as a result of parental effects or nongenetic somatic and epigenetic transmission of trait changes (Lim \& Brunet, 2013; Sunday et al., 2014). Apart from the effects found in Acartia sp. mentioned above (Vehmaa et al., 2012), such parental effects have been found in the oyster, Saccostrea glomerata, where parental exposure to $900 \mu \mathrm{atm} \mathrm{CO}_{2}$ had positive carry-over effects on larvae. Larvae spawned from adults exposed to $900 \mu \mathrm{atm} \mathrm{CO}_{2}$ were larger and developed faster than larvae from nonexposed adults (Parker et al., 2012). Moreover, genetic selection and nongenetic transgenerational effects are not mutually exclusive. Nongenetic inheritance can decouple phenotypic change from genetic change over multiple generations, and this may allow adaptation to catch up with fast environmental changes like OA (Whitlock, 1995; Bonduriansky et al., 2012). Finally, while we cannot rule out nongenetic transmission or combined effects, estimated mortalities were sufficiently high $(>50 \%$ per generation) to allow significant selection and hence genetic adaptation in all four original high $p \mathrm{CO}_{2}$ populations.

It has been argued that individuals selected for increased phenotypic plasticity resulting from changing environments may experience increased energetic costs (DeWitt et al., 1998) and that this may induce detrimental effects in the adapted population. However, the less steep reaction norms of the $1550 \mu \mathrm{atm}$ populations (i.e. the difference between original $1550 \mu$ atm populations and 1550 to $400 \mu \mathrm{atm}$ transplants) in both egg production and hatching success suggest otherwise. While individuals from the original $400 \mu$ atm populations experienced severely reduced fecundity at $1550 \mu$ atm $\mathrm{CO}_{2}$ (67\% reduction), the $1550 \mu$ atm populations upheld an only $29 \%$ diminished fecundity compared to the $400 \mu \mathrm{atm}$ populations. Moreover, the original $1550 \mu$ atm populations avoided the increase in respiration rates experienced by the $900 \mu \mathrm{atm}$ 
populations. Rather, respiration followed the decrease in egg production and was more tightly coupled to egg production probably through SDA effects (Thor, 2000). We hypothesize that the transgenerational effects may have altogether relieved the copepods from the metabolic stress they would otherwise have experienced at $1550 \mu$ atm $\mathrm{CO}_{2}$.

The three tested scenarios allowed us to cover present day as well as near-future environmental oceanic $\mathrm{pCO}_{2}$ variability (400-900 $\left.\mu \mathrm{atm} \quad \mathrm{CO}_{2}\right)$ and beyond (1550 $\left.\mu \mathrm{atm} \mathrm{CO}_{2}\right)$. In the Gullmar Fjord, average $\mathrm{pH}$ varies between 8.04 and $8.17 \mathrm{pH}$ units. However, $\mathrm{pH}$ variation is high, and values as low as 7.57 $\mathrm{pH}$ units have been recorded. The shift of all the values by $0.4 \mathrm{pH}$ units, as projected for 2100, predict values ranging from $\mathrm{pH} 8.28$ to 7.17 , with a mean annual value of $\mathrm{pH} 7.71$ (Dorey et al., 2013). Our tested scenarios therefore correspond to (i) average $\mathrm{pH}$ experienced today ( $\mathrm{pH} 8.05, p \mathrm{CO}_{2} 400 \mu \mathrm{atm}$ ); (ii) average $\mathrm{pH}$ in 2100 and extreme of present natural variability ( $\left.\mathrm{pH} 7.75, \quad p \mathrm{CO}_{2} 900 \mu \mathrm{atm}\right) ;$ and (iii) extreme $\mathrm{pH}$ in 2100 and outside of present natural variability ( $\left.\mathrm{pH} 7.54, p \mathrm{CO}_{2} 1550 \mu \mathrm{atm}\right)$. Thus, our results suggest that $P$. acuspes react with phenotypic plasticity through increased respiration and re-allocation of resources within present day's environment. When exposed to elevated $p \mathrm{CO}_{2}$ beyond present day's natural variability, transgenerational effects set in so that the copepods are able to avoid further decreases in fecundity.

Pseudocalanus acuspes exists in great numbers, and any serious effects on the genetic diversity of the global standing population are hard to imagine. But, the effects found in the present study may have other ecological implications. While a $29 \%$ decrease in fecundity is serious in terms of biomass production and trophic transport of matter, the $67 \%$ reduction without transgenerational buffering would have been catastrophic. Calanoid copepods constitute some $80 \%$ of the global zooplankton biomass (Mauchline, 1998), they support global fish stocks due to their importance as prey for many species during their larval life (Last, 1980), and Pseudocalanus constitute one of the most abundant genera. Stock recruitments of mackerel, Scomber scombrus, have been shown to covary with copepod biomass through at least two decades in the Gulf of St. Lawrence, and the emergence of two exceptional strong year classes were directly correlated with high abundances of calanoid copepods (Runge et al., 1999; Castonguay et al., 2008). Such effects have also been observed in the North Sea where survival of larval cod, Gadus morhua, has been shown to depend on size and abundance of their copepod prey (Beaugrand et al., 2003). In the Baltic Sea deep basins, increase in rainfall since the 1980s and lack of intrusion of high saline water from the North Sea have affected reproduction and maturation of a sibling species P. elongatus (Mollmann et al., 2003). Investigations of stomach contents showed that herring, Clupea harengus, have been forced to revert to less favourable prey than $P$. elongatus during this period, and this has had serious implications for herring growth and development. In view of this, OA effects in copepods will not only affect copepod populations per se but have repercussions up through the food web. On the other hand, the transgenerational alleviation of OA effects found here may partly release the constraints of OA on the pelagic ecosystem.

\section{Acknowledgements}

We thank the staff at the Sven Lovén Centre for Marine Science at Kristineberg for their skilful help and B. Svenningsen for invaluable logistic support during experiments. We also thank P. Calosi and H. Dam for improvements to the manuscript. P. Thor was financially supported by the Norwegian Ministry of Climate and Environment through the Fram Centre Flagship 'Ocean acidification and ecosystem effects in northern waters', and S. Dupont was supported by the Linnaeus Centre for Marine Evolutionary Biology at the University of Gothenburg and the Swedish Research Councils VR and Formas (Linnaeus grant). Experiments were financially supported by the European Community through ASSEMBLE grant agreement no. 227799.

\section{References}

Aarbakke ONS, Bucklin A, Halsband C, Norrbin F (2011) Discovery of Pseudocalanus moultoni (Frost, 1989) in Northeast Atlantic waters based on mitochondrial COI sequence variation. Journal of Plankton Research, 33, 14871495.

Avery DE, Dam HG (2007) Newly discovered reproductive phenotypes of a marine copepod reveal the costs and advantages of resistance to a toxic dinoflagellate. Limnology and Oceanography, 52, 2099-2108.

Beaugrand G, Brander KM, Lindley JA, Souissi S, Reid PC (2003) Plankton effect on cod recruitment in the North Sea. Nature, 426, 661-664.

Bonduriansky R, Crean AJ, Day T (2012) The implications of nongenetic inheritance for evolution in changing environments. Evolutionary Applications, 5, 192201.

Caldeira K, Wickett ME (2005) Ocean model predictions of chemistry changes from carbon dioxide emissions to the atmosphere and ocean. Journal of Geophysical Research: Oceans, 110, C09S04.

Calliari D, Andersen CM, Thor P, Gorokhova E, Tiselius P (2006) Salinity modulates the energy balance and reproductive success of co-occurring copepods Acartia tonsa and A. clausi in different ways. Marine Ecology Progress Series, 312, 177-188.

Calosi P, Rastrick SPS, Lombardi C et al. (2013) Adaptation and acclimatization to ocean acidification in marine ectotherms: an in situ transplant experiment with polychaetes at a shallow $\mathrm{CO}_{2}$ vent system. Philosophical Transactions of the Royal Society of London. Series B, Biological Sciences, 368, 20120444.

Cao L, Caldeira K, Jain AK (2007) Effects of carbon dioxide and climate change on ocean acidification and carbonate mineral saturation. Geophysical Research Letters, 34, L05607.

Castonguay M, Plourde S, Robert D, Runge JA, Fortier L (2008) Copepod production drives recruitment in a marine fish. Canadian Journal of Fisheries and Aquatic Sciences, 65, 1528-1531.

Colin SP, Dam HG (2002) Latitudinal differences in the effects of the toxic dinoflagellate Alexandrium spp. on the feeding and reproduction of populations of the copepod Acartia hudsonica. Harmful Algae, 1, 13-125. 
Cripps G, Lindeque P, Flynn KJ (2014) Have we been underestimating the effects of ocean acidification in zooplankton? Global Change Biology, 20, 33773385.

Dam HG (2013) Evolutionary adaptation of marine zooplankton to global change. Annual Review of Marine Science, 5, 349-370.

DeWitt TJ, Scheiner SM (2004) Phenotypic Plasticity. Functional and Conceptual Approaches. Oxford University Press, Oxford.

DeWitt TJ, Sih A, Wilson DS (1998) Costs and limits of phenotypic plasticity. Trends in Ecology \& Evolution, 13, 77-81.

Dorey N, Lancon P, Thorndyke M, Dupont S (2013) Assessing physiological tipping point of sea urchin larvae exposed to a broad range of $\mathrm{pH}$. Global Change Biology, 19, 3355-3367.

Drif K, Hirst AG, Hay S (2010) Seasonal abundance and egg production rates of Oithona similis and Pseudocalanus elongatus in the northern North Sea: a first comparison of egg-ratio and incubation methods. Marine Ecology Progress Series, 415, 159 175 .

Dupont S, Pörtner HO (2013) Get ready for ocean acidification. Nature, 498, 429.

Fitzer SC, Caldwell GS, Close AJ, Clare AS, Upstill-Goddard RC, Bentley MG (2012) Ocean acidification induces multi-generational decline in copepod naupliar production with possible conflict for reproductive resource allocation. Journal of Experimental Marine Biology and Ecology, 418-419, 30-36.

Fitzer SC, Caldwell GS, Clare AS, Upstill-Goddard RC, Bentley MG (2013) Response of copepods to elevated $\mathrm{pO}_{2}$ and environmental copper as co-Stressors - A multigenerational study. PLoS One, 8, e71257.

Gienapp P, Teplitsky C, Alho JS, Mills JA, Merilä J (2008) Climate change and evolution: disentangling environmental and genetic responses. Molecular Ecology, 17, 167-178.

Glazier DS, Calow P (1992) Energy allocation rules in Daphnia magna: clonal and age differences in the effects of food limitation. Oecologia, 90, 540-549.

Grabbert S, Renz J, Hirche H-J, Bucklin A (2010) Species-specific PCR discrimination of species of the calanoid copepod Pseudocalanus, P. acuspes and P. elongatus, in the Baltic and North Seas. Hydrobiologia, 652, 289-297.

Gudmundsdottir R(2008) Pseudocalanus in Svalbard waters: identification and distribution of two sibling species. Department of Aquatic Biosciences, Norwegian College of Fisheries Science, University of Tromsø, pp. 1-53.

Head EJH, Harris LR, Yashayaev I (2003) Distributions of Calanus spp. and other mesozooplankton in the Labrador Sea in relation to hydrography in spring and summer (1995-2000). Progress in Oceanography, 59, 1-30.

Henry RP, Wheatly MG (1992) Interaction of respiration, ion regulation, and acidbase-balance in the everyday life of aquatic crustaceans. American Zoologist, 32 407-416.

Hurlbert SH (1984) Pseudoreplication and the design of ecological field experiments. Ecological Monographs, 54, 187-211.

IPCC (2013) IPCC fifth assessment report: Climate Change 2013. The Physical Science Basis, Cambridge.

de Jong G (1995) Phenotypic plasticity as a product of selection in a variable environment. The American Naturalist, 145, 493-512.

Kelly MW, Hofmann GE (2013) Adaptation and the physiology of ocean acidification. Functional Ecology, 27, 980-990.

Kelly MW, Sanford E, Grosberg RK (2012) Limited potential for adaptation to climate change in a broadly distributed marine crustacean. Proceedings. Biological sciences The Royal Society, 279, 349-356.

Kroeker KJ, Kordas RL, Crim RN, Singh GG (2010) Meta-analysis reveals negative yet variable effects of ocean acidification on marine organisms. Ecology Letters, 13, 1419-1434

Kurihara $\mathrm{H}$ (2008) Effects of $\mathrm{CO}_{2}$-driven ocean acidification on the early developmental stages of invertebrates. Marine Ecology Progress Series, 373, 275-284.

Kurihara $\mathrm{H}$, Ishimatsu A (2008) Effects of high $\mathrm{CO}_{2}$ seawater on the copepod (Acartia tsuensis) through all life stages and subsequent generations. Marine Pollution Bulletin, 56, 1086-1090.

Kurihara H, Shimode S, Shirayama Y (2004) Sub-lethal effects of elevated concentration of $\mathrm{CO}_{2}$ on planktonic copepods and sea urchins. Journal of Oceanography, $\mathbf{6 0}$ 743-750.

Lardies MA, Bozinovic F (2006) Geographic covariation between metabolic rate and life-history traits. Evolutionary Ecology Research, 8, 455-470.

Last JM (1980) The Food of Twenty Species of Fish Larvae in the West-Central North Sea. Ministry of Agriculture, Fisheries and Food, Lowestoft, UK.

Lewis E, Wallace DWR (1998) Program Developed for $\mathrm{CO}_{2}$ System Calculations. Carbon Dioxide Information Analysis Center, Oak Ridge National Laboratory, US Department of Energy, Oak Ridge, TN.
Lewis CN, Brown KA, Edwards LA, Cooper G, Findlay HS (2013) Sensitivity to ocean acidification parallels natural $\mathrm{pCO}_{2}$ gradients experienced by Arctic copepods under winter sea ice. Proceedings of the National Academy of Sciences of the United States of America, 110, E4960-E4967.

Lim JP, Brunet A (2013) Bridging the transgenerational gap with epigenetic memory. Trends in Genetics, 29, 176-186.

Lonsdale DJ, Levinton JS (1985) Latitudinal differentiation in copepod growth - an adaptation to temperature. Ecology, 66, 1397-1407.

Mauchline J (1998) The Biology of Calanoid Copepods. Academic Press, San Diego, CA.

Mayor DJ, Everett NR, Cook KB (2012) End of century ocean warming and acidification effects on reproductive success in a temperate marine copepod. Journal of Plankton Research, 34, 258-262.

McConville K, Halsband C, Fileman ES, Somerfield PJ, Findlay HS, Spicer JI (2013) Effects of elevated $\mathrm{CO}_{2}$ on the reproduction of two calanoid copepods. Marine Pollution Bulletin, 73, 428-434.

Mitton JB (1997) Selection in Natural Populations. Oxford University Press, New York, NY

Mollmann C, Kornilovs G, Fetter M, Koster FW, Hinrichsen HH (2003) The marine copepod, Pseudocalanus elongatus, as a mediator between climate variability and fisheries in the Central Baltic Sea. Fisheries Oceanography, 12, 360-368.

Montagnes DJS, Berges JA, Harrison PJ, Taylor FJM (1994) Estimating carbon, nitrogen, protein, and chlorophyll $a$ from volume in marine phytoplankton. Limnology and Oceanography, 39, 1044-1060.

Munday PL, Warner RR, Monro K, Pandolfi JM, Marshall DJ (2013) Predicting evolutionary responses to climate change in the sea. Ecology Letters, 16, 1488 1500.

Niewiarowski PH, Roosenburg W (1993) Reciprocal transplant reveals sources of variation in growth rates of the lizard Sceloporus Undulatus. Ecology, 74, 1992 2002.

Parker LM, Ross PM, O'Connor WA, Borysko L, Raftos DA, Pörtner HO (2012) Adult exposure influences offspring response to ocean acidification in oysters. Global Change Biology, 18, 82-92.

Pespeni MH, Sanford E, Gaylord B et al. (2013) Evolutionary change during experimental ocean acidification. Proceedings of the National Academy of Sciences of the United States of America, 110, 6937-6942.

Pörtner HO, Langenbuch M, Reipschläger A (2004) Biological impact of elevated ocean $\mathrm{CO}_{2}$ concentrations: lessons from animal physiology and earth history. Journal of Oceanography, 60, 705-718.

Riebesell U, Fabry VJ, Hansson L, Gattuso JP (2010) Guide to Best Practice for Research for Ocean Acidification and Data Reporting. Publications Office of the European Union, Luxembourg.

Runge JA, Roff JC (2000) The measurement of growth and reproductive rates. In ICES Zooplankton Methodology Manual (eds Harris R, Wiebe P, Lenz J, Skjoldal HR, Huntley M), pp. 401-454. Academic Press, London.

Runge JA, Castonguay M, De LaFontaine Y, Ringuette M, Beaulieu JL (1999) Covariation in climate, zooplankton biomass and mackerel recruitment in the southern Gulf of St Lawrence. Fisheries Oceanography, 8, 139-149.

Saba GK, Schofield O, Torres JJ, Ombres EH, Steinberg DK (2012) Increased feeding and nutrient excretion of adult Antarctic Krill, Euphausia superba, exposed to enhanced carbon dioxide $\left(\mathrm{CO}_{2}\right)$. PLoS One, 7, e52224.

Stumpp M, Wren J, Melzner F, Thorndyke MC, Dupont ST (2011) $\mathrm{CO}_{2}$ induced seawater acidification impacts sea urchin larval development I: elevated metabolic rates decrease scope for growth and induce developmental delay. Comparative Biochemistry and Physiology Part A: Molecular \& Integrative Physiology, 160, 331 340

Stumpp M, Hu MY, Melzner F et al. (2012) Acidified seawater impacts sea urchin larvae $\mathrm{pH}$ regulatory systems relevant for calcification. Proceedings of the National Academy of Sciences of the United States of America, 109, 18192-18197.

Sunday JM, Crim RN, Harley CDG, Hart MW (2011) Quantifying rates of evolutionary adaptation in response to ocean acidification. PLoS One, 6, e22881.

Sunday JM, Calosi P, Dupont S, Munday PL, Stillman JH, Reusch TBH (2014) Evolution in an acidifying ocean. Trends in Ecology \& Evolution, 29, 117-125.

Thor P (2000) Relationship between specific dynamic action and protein deposition in calanoid copepods. Journal of Experimental Marine Biology and Ecology, 24, 171182

Thor P, Cervetto G, Besiktepe S, Ribera-Maycas E, Tang KW, Dam HG (2002) Influence of two different green algal diets on specific dynamic action and incorporation of carbon into biochemical fractions in the copepod Acartia tonsa. Journal of Plankton Research, 24, 293-300. 
Thor P, Nielsen TG, Tiselius P et al. (2005) Post spring bloom community structure of pelagic copepods in the Disko Bay, Western Greenland. Journal of Plankton Research, 27, 341-356.

Vehmaa A, Brutemark A, Engstrom-Ost J (2012) Maternal effects may act as an adaptation mechanism for copepods facing $\mathrm{pH}$ and temperature changes. PLoS One, 7 , e48538.

Vidal DE, Horne AJ (2009) Inheritance of mercury tolerance in the aquatic oligochaete Tubifex tubifex. Environmental Toxicology and Chemistry, 22, 2130-2135.

Whitlock MC (1995) Variance-induced peak shifts. Evolution, 49, 252-259.
Zervoudaki S, Frangoulis C, Giannoudi E, Krasakopoulou E (2014) Effects of low pH and raised temperature on egg production, hatching and metabolic rates of a Mediterranean copepod species (Acartia clausi) under oligotrophic conditions. Mediterranean Marine Science, 15, 74-83.

Zhang D, Li S, Wang G, Guo D, Xing K, Zhang S (2012) Biochemical responses of the copepod Centropages tenuiremis to $\mathrm{CO}_{2}$-driven acidified seawater. Water, Science, and Technology, 65, 30-37. 